\title{
ESTADO DE DETERIORAÇÃO DOS MÉIS DE ABELHA (APIS MELLIFERA) COMERCIALIZADOS EM SÃO LUÍS DO MARANHÃO*
}

\author{
STATE OF DETERIORATION OF BEE'S HONEYS (APIS MELLIFERA) COMMERCIALIZED \\ IN SÃO LUIS- MARANHÃO
}

\author{
ESTADO DE DETERIORO DEL MIEL DE ABEJA (APIS MELLIFERA) SE COMERCIALICEN \\ EN SAO LUIS DO MARANHÃO
}

\author{
Marly Azevedo Saraiva \\ Gilberth Silva Nunes \\ Ivone Garros Rosa \\ José Malheiros Silva \\ Carlene Reis Peixoto \\ Carlos Alexandre Holanda
}

\begin{abstract}
Resumo: O mel é um alimento muito apreciado e de excelente valor nutritivo, constituído por uma mistura complexa de carboidratos, enzimas, aminoácidos, ácidos, minerais, substâncias aromáticas, vitaminas, pigmentos, cera e grãos de pólen. O produto pode apresentar alterações devido a formas inadequadas de armazenamento e conservação. Tais procedimentos ocasionam sua deterioração, comprometendo seriamente o alimento. Quando os méis de abelha são submetidos a condições de temperatura e luminosidade intensa podem sofrer algumas modificações nas suas propriedades físico-químicas. A proposta deste trabalho é verificar a presença e o grau de deterioração dos méis de abelha comercializados em São Luís do Maranhão. Foram realizadas as análises físico-químicas: umidade, acidez, atividade diastásica e hidroximetilfurfural em 30 amostras de méis de Apis mellifera e os valores foram analisados segundo a Instrução Normativa n. ${ }^{\circ} 11$ de 2000 do MAPA. As amostras em estudo apresentaram valores fora dos padrões estabelecidos pela legislação, em relação à determinação de atividade diastásica e teor de hidroximetilfurfural, parâmetros físico-químicos que fornecem indicações sobre o grau de conservação e superaquecimento, o que indica que as amostras apresentaram deterioração.
\end{abstract}

Palavras-chave: Mel. Apis mellifera. Deterioração.

\begin{abstract}
Honey is a very appreciated food and has excellent nutritional value, constituted by a mixture of a complex carbohydrates, enzymes, amino acids, minerals, flavorings, vitamins, pigments, waxes and pollen. The product may undergo changes due to inadequate forms of storage and conservation. These procedures may cause their deterioration, severely compromising the food. When the honeys of bee are submitted to conditions of temperature and intense light may undergo some modifications in their physicochemical properties. The purpose of this study is to verify the presence and degree of deterioration of honeys of bee commercialized in São Luis do Maranhão. Physico-chemical analyses were done: moisture, acidity, diastase activity and hydroxymethylfurfural in 30 honey samples of Apis mellifera and the values were analyzed according to Normative Instruction No. 11 of 2000 of MAPA. The samples studied showed values outside the standards established by legislation in relation to the determination of diastase activity and hydroxymethylfurfural content, physico-chemical parameters that provide indications about the degree of conservation and overheating, which indicates that the samples showed deterioration.
\end{abstract}

Keywords: Honey. Apis mellifera. Deterioration.

Resumen: La miel es un alimento muy popular y el valor nutritivo excelente, compuesto de una mezcla de hidratos de carbono complejos, enzimas, aminoácidos, minerales, vitaminas, aromatizantes, colorantes, ceras y polen. El producto puede sufrir cambios debido a métodos inadecuados de almacenamiento y conservación. Estos procedimientos causan su deterioro, comprometiendo severamente los alimentos Cuando las abejas están sujetas a condiciones de temperatura y luz intensa pueden sufrir algunas modificaciones en sus propiedades fisicoquímicas. El objetivo de el presente estudio es verificar la presencia y el grado de deterioro de la miel de abeja negocian en São Luís do Maranhão. Los análisis se realizaron con propiedades físicoquímicas: La humedad, acidez, actividad de la diastasa y el hidroximetilfurfural en 30 muestras de miel de Apis mellifera y los valores fueron analizados de acuerdo a la Instrucción Normativa No 11 de 2000 MAPA. Las muestras estudiadas mostraron valores fuera de los estándares establecidos por la legislación en relación con la determinación de la actividad de la diastasa y el contenido de hidroximetilfurfural, parámetros físico-químicos que proporcionan información sobre el grado de conservación y el sobrecalentamiento, lo que indica que las muestras mostraron deterioro.

Palabras clave: Mel. Apis mellifera. Deterioro.

\footnotetext{
*Artigo recebido em outubro 2012

Aprovado em dezembro 2012
} 


\section{INTRODUÇÃO}

O mel é um produto natural, resultante do processamento do néctar das flores e de outras partes extraflorais pelas abelhas. Este produto é amplamente consumido devido ao seu sabor agradável e por representar uma importante fonte de energia (ALVES et al., 2009).

O mel possui uma composição química variável em sabor, aroma, coloração e teor de umidade, minerais, vitaminas e açúcares que dependem de muitos fatores: florada visitada pela abelha, natureza do solo, condições climáticas, raça das abelhas e as práticas apícolas. O néctar extraído das flores fornece ao mel consistência, cor, aroma e sabores diferentes (BONTEMPO, 2008).

É um alimento apreciado por seu sabor característico e pelo seu considerável valor nutritivo, porém sua oferta é bem menor que a procura, que torna seu preço relativamente alto, incentivando, muitas vezes, a sua adulteração, geralmente feita através de adição de açúcares comerciais, derivados de cana-de-açúcar e milho (ARAÚjO et al., 2006).

Existem cuidados especiais ao armazenar o mel, principalmente no que diz respeito à higiene do ambiente, à conservação dos méis em recipientes plásticos, de vidro ou em latas e, principalmente, em relação ao controle da temperatura. Altas temperaturas durante todo o processamento e estocagem são prejudiciais à qualidade do produto final, uma vez que é um fator contribuinte para a deterioração rápida, comprometendo assim a qualidade do mel (MELO, 2002; PEREIRA et al., 2003).

Os trabalhos de análises físico-químicas de méis são realizados com o objetivo de comparar os resultados obtidos com padrões ditados por órgãos oficiais internacionais ou com os estabelecidos pelo próprio país, deixando clara não só uma preocupação com a qualidade do mel produzido internamente, como também, tornando possível a fiscalização de méis importados com relação às suas alterações (CARVALHO et al., 2005).

Para reconhecimento do estado de deterioração do mel, as análises recomendadas pela legislação brasileira são acidez, atividade diastásica e hidroximetilfurfural (HMF). No mel, o HMF é um dos produtos de degradação mais comum, indicando "envelhecimento" do produto. Geralmente está ausente em méis recém-colhidos e sua concentração tende a crescer com o tempo (FINOLA et al., 2007), sendo assim um importante indicador de qualidade do mel (SPANO et al., 2006).
O estudo do HMF em alimentos tem recebido atenção porque este composto e seus derivados, 5-clorometilfurfural e 5-sulfoximetilfurfural, têm apresentado atividade citotóxica, genotóxica, mutagênica e carcinogênica (TEIXIDÓ et al., 2006).

A atividade diastásica é uma medida do teor de enzimas no mel e indicada para a qualidade do mesmo, pois fornece informações sobre o grau de conservação e superaquecimento, o que compromete seriamente o produto. A acidez contribui para a sua estabilidade, frente ao desenvolvimento de microrganismos. Os ácidos dos méis estão dissolvidos em solução aquosa e produzem íons de hidrogênio que promovem a sua acidez ativa, permitindo, assim, indicar as condições de armazenamento e processo de fermentação existente no produto (MARCHINI et al., 2004).

Com a crescente exigência do mercado consumidor em relação à qualidade de produtos alimentícios, existe um aumento da procura por selos de qualidade, como o do S.I.F, no caso do mel (SILVA et al., 2006).

Desta forma a proposta deste trabalho foi verificar se os méis comercializados em grandes redes de supermercados e farmácias de São Luís - MA atendem aos requisitos estabelecidos pelo Ministério da Agricultura e Abastecimento (MAPA).

\section{MATERIAIS E MÉTODOS}

Foram coletadas 30 amostras de méis da abelha Apis mellifera, sendo 6 amostras de marcas e origens distintas, nas principais redes de supermercados e farmácias de São Luís - MA, no período de junho e julho de 2008. Os méis adquiridos para o estudo possuíam informações obrigatórias nos rótulos, principalmente o item selo de inspeção (SIF).

A pesquisa foi realizada no Laboratório de Imunologia Básica e Aplicada da Universidade Federal do Maranhão.

\subsection{Análises físico-químicas}

As amostras de mel de abelha foram submetidas às análises para determinação do teor de umidade, $\mathrm{pH}$, acidez, hidroximetilfurfural e atividade diastásica. Todas as análises foram baseadas nas recomendações da Instrução Normativa n. ${ }^{\circ} 11$ de 2000 do MAPA.

$O$ teor de umidade foi determinado por refratometria utilizando-se um refratômetro de 
Abbé (ASSOCIATION OF OFFICIAL ANALYTICAL CHEMISTS, 1998).

A determinação do $\mathrm{pH}$ foi realizada por método potenciométrico utilizando-se pHgâmetro digital de mesa modelo 827 da Metrohm (ASSOCIATION OF OFFICIAL ANALYTICAL CHEMISTS, 1998).

A acidez foi determinada por método titulométrico, utilizando-se o hidróxido de sódio a $0,1 \mathrm{~mol} / \mathrm{L}$ (ASSOCIATION OF OFFICIAL ANALYTICAL CHEMISTS, 1998).

A determinação da atividade diastásica foi fundamentada na hidrólise do amido, cujo resultado foi expresso como $\mathrm{mL}$ de solução de amido a $1 \%$ hidrolisado pela enzima em $10 \mathrm{~g}$ de mel, durante 1 hora. As leituras das amostras foram realizadas em espectrofotômetro UV, no comprimento de onda de $660 \mathrm{~nm}$ (CODEX ALIMENTARIUS COMMISSION, 1990).

O teor de hidroximetilfurfural foi determinado através do método quantitativo, que consiste na verificação do $\mathrm{HMF}$, utilizando-se um espectrofotômetro nos comprimentos de onda entre 284 e 336nm (ASSOCIATION OF OFFICIAL ANALYTICAL CHEMISTS, 1998).

Os resultados foram analisados através do software estatístico SPSS for Windows 16.0 (2007), aplicando-se o teste t de Student para as variáveis (umidade, $\mathrm{pH}$, acidez, atividade diastásica e hidroximetilfurfural).

\section{RESULTADOS E DISCUSSÃO}

Os resultados das análises físico-químicas, em comparação aos valores padronizados pela a legislação vigente do Ministério da Agricultura e do Abastecimento que estabelece um valor máximo de $20 \%$ de umidade (BRASIL, 2000).

Pesquisadores como Abadio Finco, Moura e Silva (2010) analisando méis comercializados nos Estados do Tocantins, Bahia e Rio Grande do Norte, também, obtiveram resultados semelhantes para o teor de umidade.

Araújo et al. (2006) encontraram teor de umidade acima do permitido em $30 \%$ de amostras comercializadas no Estado do Ceará, sugerindo que esses méis são oriundos de favos não operculados ou ainda período e/ou condições de armazenamento inadequadas.

Os dados relativos à acidez demonstram que as amostras de méis apresentaram uma média de 27,28 mEq/ $\mathrm{kg}$, estando de acordo com as normas da legislação vigente, que estabelece um máximo de $50 \mathrm{mEq} / \mathrm{kg}$ de mel (BRASIL, 2000).

Bendini et al. (2008) encontraram valor médio para acidez de 30,21 Meq. $\mathrm{Kg}-1 \mathrm{em}$ méis provenientes da florada do cajueiro e atribuíram às características físicas e químicas encontradas nas amostras à especificidade da florada.

Os valores de $\mathrm{pH}$ para as amostras de méis analisados variaram pouco, na faixa de 3,6 a 4,4 e todas estavam dentro do recomendado que é de 3,3 a 4,6 (BARTH et al., 2005). Essa faixa de $\mathrm{pH}$ baixa pode influenciar na estabilidade do produto frente ao desenvolvimento de microrganismos

Com relação à atividade diastásica, as amostras de méis apresentaram uma média de 4,8 unidades de diastase, discordando com

Tabela 1 - Comparação entre os valores médios experimentais das análises físico-químicas realizadas e valores padronizados pela Legislação brasileira para méis de Apis Mellifera comercializados nas principais redes de supermercados e farmácias de São Luís - MA $(n=30)$.

\begin{tabular}{c|c|c|c|c|c}
\hline & Umidade (\%) & $\mathbf{p H}$ & $\begin{array}{c}\text { Acidez } \\
(\mathbf{m E q} / \mathbf{K g})\end{array}$ & $\begin{array}{c}\text { Atividade } \\
\text { diastásica } \\
\text { (Escala de Gothe) }\end{array}$ & $\begin{array}{c}\text { Hidroximetilfurfural } \\
\mathbf{( m g / K g )}\end{array}$ \\
\hline Mínimo & 17,0 & 3,6 & 17,0 & 2,8 & 46,4 \\
\hline Máximo & 20,8 & 4,4 & 45,3 & 9,3 & 103,5 \\
\hline Média & 18,8 & 3,9 & 27,2 & 4,8 & 66,9 \\
\hline Desvio Padrão & 1,2 & 0,2 & 8,7 & 1,3 & 19,3 \\
\hline Limites da legislação* & $\leq 20$ & - & $\leq 50$ & $\geq 8$ & $\leq 60$ \\
\hline
\end{tabular}

* Fonte: BRASIL, Instrução Normativa No. 11, de 20/10/2000

Instrução Normativa n.0 11 de 2000, estão contidos na Tabela 1.

Em relação ao teor de umidade, as amostras de méis em estudo apresentaram uma média de $18,8 \%$, estando de acordo com os padrões técnicos de identidade e qualidade do mel, segundo a legislação que estabelece um mínimo de 8 unidades de diastase na escala de Gothe e 3 na mesma escala se o hidroximetilfurfural for menor ou igual a $15 \mathrm{mg} / \mathrm{kg}$ (BRASIL, 2000).

$\mathrm{Na}$ determinação da atividade diastásica, Marchini et al. (2004), ao analisarem méis 
comercializados nos Estados da Bahia e Ceará, encontraram valores de atividade diastásica de acordo com as normas estabelecidas pela legislação.

White Júnior (1994), citado por Marchini et al. (2004) questionou o uso da atividade distásica como indicadora de qualidade do mel devido a grande variação na quantidade de diástase em méis recém-colhidos e não aquecidos.

Em relação ao teor de hidroximetilfurfural, as amostras em estudo apresentaram uma média de $66,99 \mathrm{mg} / \mathrm{kg}$, acima de 60 $\mathrm{mg} / \mathrm{kg}$, o máximo permitido pela legislação (BRASIL, 2000).

Caso os méis fossem destinados ao mercado externo, todas as amostras não estariam em conformidade para níveis de hidroximetilfurfural, considerando que o MERCOSUL e a União Europeia estabelecem em limite máximo de $40 \mathrm{mg} / \mathrm{kg}$ de HMF (MERCOSUL, 1999; UNIÃO EUROPEIA, 2001).

Além do armazenamento em temperaturas elevadas, o aumento do conteúdo de HMF no mel também é influenciado pela adição de açúcar invertido, acidez, pH, água e minerais (MARCHINI et al., 2004).

As amostras analisadas que apresentaram valores fora da legislação para o critério de deterioração podem sugerir um armazenamento inadequado e exposição direta à luz artificial.

\section{CONSIDERAÇÕES FINAIS}

As amostras dos méis de Apis mellifera em estudo apresentaram valores para os parâmetros de umidade, acidez e atividade diastásica de acordo com a legislação do Ministério da Agricultura e do Abastecimento.

Em relação ao teor de HMF, observou-se que $46,6 \%$ das amostras estavam com valores acima do permitido pela legislação brasileira para méis de abelha do gênero Apis.

Os dados apresentados no trabalho mostram a importância de verificar as condições em que os méis são armazenados e transportados para as redes comerciais, oferecendo assim segurança para os consumidores.

\section{AGRADECIMENTOS}

Os autores agradecem a Universidade Federal do Maranhão e a Universidade Estadual do Maranhão pela disponibilidade dos laboratórios para a realização das análises e ao Banco do Nordeste pelo financiamento para desenvolvimento do projeto. Marly Azevedo Saraiva agradece ao Programa Institucional de Bolsas de Iniciação Científica (PIBIC/CNPQ) pela bolsa de iniciação científica concedida.

\section{REFERÊNCIAS}

ABADIO FINCO, F. D. B.; MOURA, L. L.; SILVA, I. G. Propriedades físicas e químicas do mel de Apis mellifera L. Ciência e Tecnologia de Alimentos, Campinas, v. 30, n. 3, p. 706-712, jul./set., 2010.

ALVES, E. M. et al. Presença de coliformes, bolores e leveduras em amostras de mel orgânico de abelhas africanizadas das ilhas do alto rio Paraná. Ciência Rural, Santa Maria, v. 39, n. 7, p. 2222-2224, 2009.

ARAÚJO, D. R. et al. Avaliação da qualidade físico-química do mel comercializado na cidade de Crato, CE. Revista de Biologia e Ciências da Terra, Campina Grande, v. 6, n. 1, p. 51 - 55, 2006.

ASSOCIATION OF OFFICIAL ANALYTICAL CHEMISTS. Official Methods of Analysis. 16.ed., 1998. 2v.

BARTH, M. O. et al. Determinação de parâmetros físico-químicos e da origem botânica de méis indicados monoflorais do sudeste do Brasil. Ciência e Tecnologia de Alimentos, Campinas, v. 25, n. 2, p. 229-233, abr./jun., 2005.

BENDINI, J. N. et al. Physicochemical characterization of the bee honey originating in cashew flowering. Ciência Rural, v. 38, n. 2, p. 565-567, 2008.

BRASIL, 2000. Ministério da Agricultura e do Abastecimento. Instrução normativa no 11 , de 20 de outubro de 2000. Seção 1, n. 204, p. $15-17$.

BONTEMPO, Marcio. Mel: uma vida doce e saudável. São Paulo: Alaúde Editorial. 2008.

CARVALHO, C. A. L. de et al. Mel de abelha sem ferrão: contribuição para a caracterização físico-química. Cruz das Almas: UFBA/SEAGRI-BA, 2005.

\section{CODEX ALIMENTARIUS COMMISSION}

(C.A.C.). Official methods of analysis. v. 3, supl. 2, 1990.

FINOLA, M. S. et al. Microbiological and chemical characterization of honey from central Argentina. Food Chemistry, v. 100, n. 4, p. 1649-1653, 2007.

MARCHINI, L. C. et al. Mel Brasileiro: composição e normas. Ribeirão Preto: [s.n.] 2004.

MELO, Z. F. N. Características físico-químicas de méis de abelha (Apis mellifera L.) em diferentes condições de armazenamento. 
2002. 71 f. Dissertação (Mestrado em Engenharia Agrícola) - Universidade Federal de Campina Grande, Campina Grande, PB, 2002.

MERCOSUL. Resolução n.89/99, de 18 de novembro de 1999. Regulamento Técnico MERCOSUL dispõe sobre a identidade e qualidade do mel. In: AGÊNCIA NACIONAL DE VIGILÂNCIA SANITÁRIA. Disponível em: <http://www.anvisa.gov.br/legis/resol/ mercosul/alimentos/89_99.htm.>. Acesso em: 10 dez. 2010.

PEReirA, F. de M. et al. Produção de mel. Sistema de produção 3 (Versão eletrônica). Embrapa Meio-Norte, 2003.

SILVA, A. F. et al. Perfi I de consumidor e aceitação de mel de abelha (Apis mellifera) Composto. In: CONGRESSO BRASILEIRO DE CIÊNCIA E TECNOLOGIA DE ALIMENTOS, 20., 2006, Curitiba. Anais... Curitiba: SBCTA, 2006. CD-ROM.
SPANO, N. et al. An RP-HPLC determination of 5 -hydroxymethylfurfural in honey. The case of strawberry tree honey. Talanta, v. 68, n. 4, p. 1390-1395, 2006.

TEIXIDÓ, E. et al. Analysis of 5-hydroxymethylfurfural in foods by gas chromatography-mass spectrometry. Journal of Chromatography A, v. 1135 , n. 1, p. 8590, 2006.

UNIÃO EUROPÉIA. Comissão do Conselho Europeu. Diretiva CE $n^{\circ} 110$, de 20 de dezembro de 2001. Define as normas comuns para o mel adaptando-as a legislação geral aplicada a produtos alimentícios. Bruxelas: EU, 2001. Disponível em:<http://eurlex. europa.eu/LexUriServ/LexUriServ.do?uri=0 J:L:2002:010:0047:0052:EN:PDF>. Acesso em: 10 dez. 2010.

WHITE JÚNIOR, J. W. The role of HMF and diástase assays in honey quality evaluation. Bee World, v. 75, n. 3, p. 104-107, 1994. 